\title{
Editorial - Volume 2, Number 2: Status Update
}

Citation: Wigton, N. L., \& Cannon, R. L. (2015). Editorial - Volume 2, Number 2: Status Update. NeuroRegulation, 2(2), 58-59. http://dx.doi.org/10.15540/nr.2.2.58

Copyright: $\odot$ 2015. Wigton and Cannon. This is an Open Access article distributed under the terms of the Creative Commons Attribution License (CC-BY).

*Address correspondence to: Nancy Wigton, PhD, Applied Neurotherapy Center, 10200 N. 92nd Street, Suite 120, Scottsdale, AZ 85258, USA. Email: nwig@cox.net

As we go to press with this second issue of Volume 2, NeuroRegulation celebrates its one-year publication anniversary! As such, we would like to take this opportunity to update you on the status of the official journal of the International Society for Neurofeedback and Research (ISNR).

ISNR members should be aware that NeuroRegulation is better considered an extension, or renaming, of the prior Journal of Neurotherapy (JNT); which published a total of 17 volumes dating back to 1995. Therefore, while NeuroRegulation may be midway into its second volume, it has in essence, close to a 20-year history. As was discussed in the inaugural issue (Clarke, 2014), ISNR made the decision to move to an electronic Open Access (OA) format to make neurotherapyand psychophysiology-related literature more accessible to a much wider audience (consumers and researchers alike), improve the publication speed, and keep pace with growing publishing trends in all academic fields. However, had ISNR moved to an OA format with the JNT publisher at the time, it would have required substantial costs to authors; rather, transitioning to an independent publishing platform facilitated an OA model with no author processing charges. We are pleased to report-in the time frame of 12 months and six issues-we are well on the way to meeting these goals. The objective of expedited publication timelines is being met with current averages of 20 days from submission to review and 60 days from submission to publication.

Evidence of attaining the accessibility goal comes from comparing times viewed reports between the current to prior journals. The NeuroRegulation times viewed/downloaded reports, in comparison to JNT most viewed articles, when adjusted for an annualized comparison, reveal that articles are being viewed at a rate more than double that of the JNT articles; with views of abstracts twice that of articles. Moreover, the JNT most viewed article (Hammond, 2011) has been accessed 4,345 times in the 44 months since publication; yet, the
NeuroRegulation abstract of Montopoli et al. (2015) has been viewed 4,799 times in only 86 days. Clearly, then, this journal with the electronic OA format, with all content accessible via Internet search engines, is being seen with greater frequency and reaching a wider audience than the prior subscription-model print journal.

Given the growing expectation of European research venues that scientific works be published in OA outlets, standards for OA journals are coming from that region. In an April press release, Science Europe (2015), a Brussels-based society made up of 50 public research organizations from 27 countries to promote their collective interests, announced their establishment of four essential principles for $O A$ journals. The aim of these OA journal standards is to ensure technical and scholarly quality in all fields, inclusive of science and social science. The standards are as follows:

1. Be indexed in a standard database such as Directory of Open Access Journals (DOAJ), Thomson-Reuter's Web of Science (TRWoS), or PubMed.

2. Publish under an open license (i.e., Creative Commons) such that the author holds the copyright with no restrictions.

3. Maintain sustainable archiving of content with a persistent address where the full publication can be accessed.

4. Publish the full text, metadata, citations, and OA status in machine-readable format using open standards.

We are pleased to report that NeuroRegulation meets all criteria. With regard to indexing, earlier this year the journal was indexed in DOAJ, currently have applications pending with both TR-WoS and PsychINFO, and have plans to apply for PubMed indexing as soon as eligible, projected by the end of this year.

We are invested in establishing NeuroRegulation as a premier publication in the field of applied 
neuroscience. Adhering to high standards for OA publishing and sound science will move us forward to that end. We aim to attract manuscripts from a wide spectrum of neuromodulatory topics and psychophysiology focus, which will position this journal to be an important global scholarly outlet for the neuroscience community.

We are appreciative of the authors who submitted their work to this issue and welcome future submissions to the journal. We invite you to join us in our efforts by contributing research, reviews, case studies, or theoretical papers. Submissions are accepted on an ongoing basis throughout the year; however, deadlines for inclusion in specific issues are posted as Announcements on the home page of the journal website.

Nancy L. Wigton, PhD, LPC, BCN, QEEGD

Executive Editor

Email: nwig@cox.net

Rex L. Cannon, PhD, BCN

Editor-in-Chief

Email: rexcannon@gmail.com

\section{References}

Clarke, A. R. (2014). Editorial - Volume 1, Number 1. NeuroRegulation, 1(1), 2-3.

http://dx.doi.org/10.15540/nr.1.1.2

Hammond, D. C. (2011). What is neurofeedback: An update. Journal of Neurotherapy, 15(3), 305-336. http://dx.doi.org/10.1080/10874208.2011.623090

Science Europe. (2015). New Science Europe Principles on Open Access Publisher Services [Press release]. Retrieved from http://www.scienceeurope.org/uploads/PressReleases/27041 5_Open_Access_New_Principles.pdf

Montopoli, M., Stevens, L., Smith, C. J., Montopoli, G., Passino, S., Brown, S., ... Wu, J. (2015). The Acute Electrocortical and Blood Pressure Effects of Chocolate. NeuroRegulation, 2(1), 3-28. http://dx.doi.org/10.15540/nr.2.1.3

Published: July 15, 2015 